\title{
Adolescent development of the reward system
}

\author{
Adriana Galvan ${ }^{1,2 *}$ \\ 1 Department of Psychology, University of California at Los Angeles, Los Angeles, CA, USA \\ 2 Brain Research Institute, University of California at Los Angeles, Los Angeles, CA, USA
}

\author{
Edited by: \\ Elizabeth D. O'Hare, \\ University of California at Berkeley, \\ USA \\ Reviewed by: \\ Larry Steinberg, Temple University, \\ USA \\ Susan L. Anderson, McLean Hospital, \\ USA

\section{*Correspondence:} \\ Adriana Galvan, Laboratory for \\ Developmental Neuroscience, \\ Department of Psychology, Brain \\ Research Institute, University of \\ California at Los Angeles, 1285 Franz \\ Hall, Box 951563, Los Angeles, CA \\ 90095-1563, USA \\ e-mail:agalván@ucla.edu
}

\begin{abstract}
Adolescence is a developmental period characterized by increased reward-seeking behavior. Investigators have used functional magnetic resonance imaging (fMRI) in conjunction with reward paradigms to test two opposing hypotheses about adolescent developmental changes in the striatum, a region implicated in reward processing. One hypothesis posits that the striatum is relatively hypo-responsive to rewards during adolescence, such that heightened reward-seeking behavior is necessary to achieve the same activation as adults. Another view suggests that during adolescence the striatal reward system is hyper-responsive, which subsequently results in greater reward-seeking. While evidence for both hypotheses has been reported, the field has generally converged on this latter hypothesis based on compelling evidence. In this review, I describe the evidence to support this notion, speculate on the disparate fMRI findings and conclude with future areas of inquiry to this fascinating question.
\end{abstract}

\section{Keywords: adolescence, brain development, striatum, reward}

\section{INTRODUCTION}

Adolescence is a developmental period characterized by increased reward-seeking behavior. This anecdotal and empirical observation has motivated the field of developmental cognitive neuroscience to identify the neural substrates of this phenomenon. As extensive animal and human work has identified the dopaminerich striatum as the seat of reward sensitivity in the brain (e.g., Schultz, 1998; Montague et al., 2004), this region has been the focus of intense study in the adolescent reward literature and is the focus of this review. Findings on other regions (e.g., the orbitofrontal cortex) that also receive rich dopamine innervation and that are implicated in reward sensitivity are not discussed here. While studies to date agree that the striatum is the neural region most responsive to reward across development, from children to adults, the relative engagement of this neural system during adolescence is a topic of debate. In this review, I begin by briefly reviewing insights from the animal literature regarding reward-related striatal development. A subsequent section reviews developmental neuroimaging findings and outlines plausible explanations and speculations for the discrepancies across studies. Finally, I conclude with caveats and future directions of this captivating area of research.

\section{THEORIES OF REWARD-DRIVEN BEHAVIOR IN ADOLESCENCE}

To assert that dramatic behavioral changes occur during adolescence is an understatement (Dahl, 2004; Steinberg, 2005; Somerville et al., 2009). The field has generally assumed and agreed upon the notion that these behavioral changes are largely driven by rewards, including monetary, novel and social rewards, and by extension, the reward-sensitive dopamine system. Less understood is how the reward system changes across development to encourage the reward-driven behaviors adolescents often exhibit.
There are two primary theories about adolescent reward behavior that center around two opposing possibilities: is the striatal system hypo- or hyper-responsive to rewards during adolescence? Some theorists have proposed that adolescent reward-seeking and risk taking might result from a relative deficit in the activity of motivational circuitry (Blum et al., 1996, 2000; Bjork et al., 2004) such that more intense or more frequent rewarding stimuli are necessary to achieve the same activation as adults. This view is likely an extension of a theory of adolescent anhedonia, which is the inability to feel pleasure (Larson and Asmussen, 1991). Support for this theory comes from data showing differences between adolescents and other ages in the perception of pleasure. For instance, human adolescents exhibit an increase in negative affect and depressed mood relative to older and younger adults (Rutter et al., 1976; Larson and Asmussen, 1991) and also appear to experience the same positive situations as less pleasurable than adults (as based on self-reports) (Watson and Clark, 1984). Adolescents also find sweetness (sugar) less pleasant than children (DeGraff and Zandstra, 1999). Based on these data, some speculate that adolescents may generally attain less positive feelings from rewarding stimuli, which drives them to purse new appetitive reinforcers through increases in reward-seeking that increase activity in dopamine-related circuitry (Spear, 2000). An opposing theory postulates that disproportionately increased activation of the ventral striatal dopamine circuit (that is, the increased dopaminergic release in response to rewarding events during adolescence) underlies adolescent reward-related behavior (Chambers et al., 2003). This view arises from extensive work on dopamine and its principal role in the translation of encoded motivational drives into action (Panksepp, 1998). This theory posits that adolescent behavior is driven by reward-related appetitive systems. Based on a majority of the work reviewed below, the field has generally converged on this latter theory; that is, that adolescents are, in part, motivated to engage in high reward behaviors because of 
developmental changes in the striatum that confer hypersensitivity to reward (e.g., Ernst et al., 2009). However, data in support of the hypo-responsiveness hypothesis are reviewed as well.

\section{STRIATAL DOPAMINE DEVELOPMENT}

Investigations in humans can only examine in vivo striatal development at a systems level using neuroimaging methods. This methodological limitation precludes precise identification of how the dopamine system changes developmentally at the neural level. Rather, the link between striatal response to reward is only an index of presumed dopamine activity. These assumptions are based on insights gleaned from animal models of striatal circuitry and the dopamine system (e.g., Berridge and Robinson, 1998). As such, they are reviewed briefly here.

Available evidence suggests that there are significant alterations in the dopamine system across development, and in particular, during adolescence. Dopamine levels increase in the striatum during adolescence (Teicher et al., 1993; Andersen et al., 1997). However, other reports have shown that young adolescent rats also display lower estimates of dopamine synthesis in the nucleus accumbens (NAcc) relative to older adolescent animals and lower NAcc dopamine turnover rates relative to adults. Stamford (1989) work showed an apparent resolution to these different results by reporting a reduced basal rate of dopamine release but a larger dopamine storage pool in periadolescent, relative to adult, rats (Stamford, 1989). In fact, dopaminergic neurons in the adolescent, despite reduced dopamine release in basal conditions (Stamford, 1989; Andersen and Gazzara, 1993), are actually able to release more dopamine, if stimulated by environmental and/or pharmacological challenges (Laviola et al., 2001). Bolanos et al. (1998) showed that striatal slices from adolescent rats were more sensitive to the dopamine uptake inhibitors cocaine and nomifensine than adults, which is in contrast to the diminished behavioral responsivity to these dopamine agonists during adolescence that the same group has reported. Together, these data suggest that, during adolescence, rewarding events may result in larger dopamine release, when compared to adults (Laviola et al., 2003). So, if indeed it is the case that adolescent animals have lower basal rates of dopamine release, then perhaps adolescents initially seek out more stimulation (rewards) that will increase dopamine release; once stimulated, however, the adolescent will show greater dopamine release that subsequently contributes to a reinforcing feedback cycle that motivates additional reward-seeking behavior.

\section{DEVELOPMENTAL CHANGE IN DOPAMINE RECEPTORS}

Several reports have noted that there is dopamine receptor overproduction followed by pruning during adolescence (Teicher et al., 1995). Striatal and NAcc dopamine receptor binding of $D_{1}$ and $D_{2}$ receptors peaks in adolescence ( $\mathrm{P} 40$ ) at levels that are about $30-45 \%$ greater than those seen in adulthood (Teicher et al., 1995; Tarazi et al., 1998, 1999). Using autoradiography in male and female rats, Andersen et al. (1997) showed a sexual dimorphism of this effect, such that adolescent males had greater overproduction (approximately 4.6-fold) and elimination of striatal $\mathrm{D}_{1}$ and $\mathrm{D}_{2}$ striatal receptors than adolescent females. Interestingly, these effects are not mediated by gonadal hormone surges (Andersen et al., 2002) but do appear to have functional consequences (Andersen and Teicher,
1999) that may correspond with behavior. A similar pattern is observed in prefrontal cortex, albeit with a more protracted elimination period (Andersen and Teicher, 2000). Confocal microscopy has revealed that retrogradely traced cortical output neurons in the prefrontal cortex express higher levels of $\mathrm{D}_{1}$ receptors during adolescence than older or younger rodents (Brenhouse et al., 2008). These rodent findings coincide with human postmortem work. Seeman et al. (1987) reported notable changes in dopamine receptor populations in human striatum during the juvenile-to-adult period, with one-third to one-half or more of the dopamine $\mathrm{D}_{1}$-like and $\mathrm{D}_{2}$-like receptors present in the striatum of juveniles being lost by adulthood. Developmental declines in $\mathrm{D}_{1}$ receptors from infancy to adulthood in humans have been also been reported by others (Palacios et al., 1988; Montague et al., 1999). Together, these animal and postmortem findings suggest that the dopamine system in adolescence may predispose individuals in this age group to greater reward sensitivity. In subsequent sections, I describe neuroimaging data that has built on these findings to show similar developmental patterns of change at the systems level.

\section{INSIGHTS FROM NEUROIMAGING}

Magnetic resonance imaging (MRI) methods introduced a new set of noninvasive tools for capturing brain development in humans. MRI is particularly useful in the study of children and adolescents as it provides precise, high-resolution anatomical images without the use of ionizing radiation (Kennedy et al., 2003). Although total brain size is approximately $90 \%$ of its adult size by age 6 (Casey et al., 2005), the gray and white matter subcomponents continue to undergo changes throughout adolescence (Giedd et al., 1999; Sowell et al., 2003; Gogtay et al., 2004). Specifically, there is a significant decrease in cortical gray matter by 12 years (Giedd et al., 1999) and an increase in cerebral white matter throughout childhood and young adulthood (Caviness et al., 1996). Recent data suggest that gray matter volume has an inverted U-shape pattern, with greater regional variation than white matter (Sowell et al., 1999, 2003; Gogtay et al., 2004). Particularly relevant to a review about the development of the dopamine system is evidence showing that the dopamine-rich frontal and striatal regions undergo significant maturational changes through adolescence (Giedd et al., 1996; Sowell et al., 1999), with a volumetric decrease in regions of the basal ganglia (Giedd et al., 1996, 1999). Similar to rodent findings, brain regions show sexual dimorphism across regions. Caudate volumes decrease during the adolescent years and are relatively larger in females (Giedd, 2004). In contrast to parietal, temporal and occipital lobes, large anatomical differences emerge between adolescents and adults in the frontal lobes and in the striatum (Sowell et al., 1999), suggesting that these two regions are relatively immature in adolescence compared to adulthood. Further, these findings suggest continued plasticity in these regions that may mediate dopamine-related behaviors and learning.

Functional MRI (fMRI) provides a measurement of brain activation that captures changes in blood oxygenation in the brain that are assumed to reflect changes in neural activity (Bandettini and Ungerleider, 2001; Logothetis et al., 2001). To study development of the dopamine system in humans, investigators have examined neurodevelopment in neural regions known to be rich 
in dopamine cell bodies and projections, mainly midbrain, striatal and prefrontal regions (Koob and Swerdlow, 1988). As fMRI is simply a presumed index of neuronal activity, studies that utilize this tool cannot definitely conclude changes in dopamine expression and/or activity. However, by using converging methods and insights from animal models, work in humans can begin to further probe the development of dopamine-rich circuitry. To do so, initial studies have used reward paradigms as a way to tap into this circuitry, given reports in adult humans showing the robust effect of reward on eliciting striatal activity (e.g., Knutson et al., 2001; Montague and Berns, 2002). Developmental studies have shown that, indeed, children and adolescents recruit the same neural circuitry that adults do when presented with monetary and nonmonetary rewards (e.g., Bjork et al., 2004; Ernst et al., 2005; Galván et al., 2006; van Leijenhorst et al., 2009). However, how adolescents differ from adults in neural recruitment has been the subject of debate in the cognitive developmental neuroscience literature.

\section{DISPARATE FMRI FINDINGS OF REWARD SENSITIVITY IN ADOLESCENTS}

Developmental fMRI studies of reward have yielded two main findings that directly map onto the two hypotheses outlined above. The first suggests that adolescents, relative to adults, show less engagement of the ventral striatum in anticipation of reward (Bjork et al., 2004). Bjork and colleagues compared early and mid-adolescents to a group of adults on the monetary incentive delay (MID) task, which was designed for and has been widely used in adult samples (e.g., Knutson et al., 2001). In the MID task, participants were first presented with one of seven cues. After a delay, they were asked to press the target and finally, feedback was presented to notify participants whether they had won or lost money during the trial. Despite similar behavioral performance, the authors found significant neural differences between age groups, such that adolescents showed less ventral striatal activation in anticipation of reward compared to adults. There were no group differences in response to feedback. Bjork and colleagues interpreted these data as support for the hypothesis that adolescents have a ventral striatal activation deficit. That is, that adolescents engage in extreme incentives (e.g., risky behaviors) 'as a way of compensating for low ventral striatal activity (Spear, 2000; Bjork et al., 2004)'.

Although Bjork and colleagues have more recently replicated these findings in a doubled sample size and using an improved headcoil (Bjork et al., in preparation, personal communication), numerous papers have reported the opposite results (May et al., 2004; Ernst et al., 2005; Galván et al., 2006; van Leijenhorst et al., 2009). These studies have shown that, relative to other age groups, adolescents show greater activation in the ventral striatum in response to reward. For instance, in our work, children, adolescents and adults were asked to perform a simple, youth-friendly task in the scanner in which different reward values were delivered following correct responses (Galván et al., 2006). Relative to children and adults, the adolescent group showed heightened ventral striatal activation in anticipation of reward. In another example, Ernst et al. (2005) used a probabilistic monetary reward task to show that adolescents recruited significantly greater left NAcc activity than adults during winning trials. These findings directly contrast the Bjork paper and lend support for the hypothesis that dispropor- tionately increased activation of the ventral striatal motivational circuit characterizes adolescent neurodevelopment and behavior (Chambers et al., 2003). A recent paper by van Leijenhorst et al. (2009) supports the hyper-responsive view as well. In contrast to the majority of similar work, they used an fMRI paradigm that was not dependent on behavior. That is, participants passively viewed stimuli that either certainly or uncertainly predicted subsequent reward. This approach is particularly important because previous studies may have been confounded by the behavioral component of the tasks. Their main finding is that adolescents show greater striatal activation than children or adults in response to reward receipt (van Leijenhorst et al., 2009), suggesting that even when reward is not contingent on behavior and thus there are no differences in motivation, adolescents show a hyper-active striatal response to reward.

These opposing findings further fuel the debate about how the dopamine system is altered during adolescence and mirror the seemingly contrasting findings of basal versus stimulated dopamine release in rodents. Given that there is relatively more evidence in support of the latter view, recent reviews on this topic suggest that the field has converged on the notion that, during adolescence, the striatal system is hyper-responsive to rewards and incentives (Ernst et al., 2009; Somerville et al., 2009). However, it is important to consider some plausible explanations for the disparate results.

\section{POSSIBLE EXPLANATIONS FOR THE DISCREPANCIES}

There are several possible explanations for the striking differences between studies. Table 1 summarizes the major areas of divergence in the most commonly cited papers on this topic. This table is not intended to be exhaustive and only includes work conducted in typically developing youth; data from clinical populations are not discussed. First, the studies differ greatly in the developmental stages and ages of participants. Second, studies differ in the comparison groups. Last, differences in task design, analysis and baseline conditions can lead to significant differences in interpretation. Where appropriate, suggestions and possible strategies to minimize these methodological differences in future work are described.

\section{What is adolescence?}

A significant issue that is underappreciated across and between studies is the problem of defining adolescence in humans. Adolescence can and is defined by a myriad ways, including age, sexual maturation, puberty, educational grade, the law, and/or financial independence, by a multitude of experts including educators, scientists, policy makers and parents. Given the seemingly endless possible definitions, adolescent researchers face a daunting task in deciding which individuals to include in their "adolescent" sample. Some scientists have identified adolescence as 'the gradual period of transition from childhood to adulthood (Spear, 2000; Dahl, 2004)'. While this broad definition is useful when describing heterogeneous bodies of work, as in literature reviews, it is not the most suitable way to define participant samples to be included in developmental studies. The reason this is inappropriate for empirical work is because of the vast heterogeneity that characterizes adolescence biologically and socially. 
Table 1 | Developmental fMRI reward studies.

\begin{tabular}{|c|c|c|c|c|c|c|}
\hline Study & Main findings & $\begin{array}{l}\text { Age range of } \\
\text { adolescent group }\end{array}$ & $\begin{array}{l}\text { Comparison } \\
\text { group }\end{array}$ & Task design & Analysis focus & Baseline \\
\hline $\begin{array}{l}\text { Bjork et al. } \\
\text { (2004) }\end{array}$ & $\begin{array}{l}\text { Adolescents show } \\
\text { hypo-responsive striatal } \\
\text { activity relative to adults }\end{array}$ & $12-17$ & $\begin{array}{l}\text { Adults } \\
\text { (ages 21-28) }\end{array}$ & $\begin{array}{l}\text { Reward } \\
\text { magnitude }\end{array}$ & $\begin{array}{l}\text { Anticipation } \\
\text { of reward }\end{array}$ & Entire trial \\
\hline $\begin{array}{l}\text { May et al. } \\
(2004)\end{array}$ & No comparison group & $9-16$ & None & $\begin{array}{l}\text { Reward } \\
\text { probability }\end{array}$ & Entire trial & $\begin{array}{l}\text { First timepoint } \\
\text { of each trial }\end{array}$ \\
\hline $\begin{array}{l}\text { Galván et al. } \\
\text { (2006) }\end{array}$ & $\begin{array}{l}\text { Adolescents show } \\
\text { hyper-responsive } \\
\text { striatal activity relative } \\
\text { to children and adults }\end{array}$ & $13-17$ & $\begin{array}{l}\text { Children } \\
\text { (ages 7-11) and } \\
\text { adults (ages 23-29) }\end{array}$ & $\begin{array}{l}\text { Reward } \\
\text { magnitude }\end{array}$ & Anticipation & Intertrial interval \\
\hline $\begin{array}{l}\text { Geier et al. } \\
\text { (2009) }\end{array}$ & $\begin{array}{l}\text { Adolescents show } \\
\text { hypo-responsive striatal } \\
\text { activity to reward cues and } \\
\text { hyper-responsive activity in } \\
\text { anticipation of reward } \\
\text { relative to adults }\end{array}$ & $13-17$ & Adults (ages 18-30) & $\begin{array}{l}\text { Reward } \\
\text { probability }\end{array}$ & $\begin{array}{l}\text { Cue, anticipati- } \\
\text { on and feedback }\end{array}$ & $\begin{array}{l}\text { Implicit baseline } \\
\text { (e.g., non-task } \\
\text { activation) }\end{array}$ \\
\hline
\end{tabular}

While some groups restricted inclusion of the adolescent sample to high school students (Galván et al., 2006; Geier et al., 2009) and one group included an age-restricted adolescent group that inarguably captured adolescence (van Leijenhorst et al., 2009), the age range of the adolescent group in the remaining studies listed in Table 1 varies widely. For instance, the Bjork et al. (2004), May et al. (2004) and Ernst et al. (2005) studies included 12-year-old children (the latter studies included even younger children, at 9 years old) in their "adolescent" sample. While a 12-year-old might be considered an early adolescent in some academic circles, it would be hard to make the same claim for a 9-year-old. Besides, even if a 12-year-old can be considered an early or pre-adolescent, that individual is a very different adolescent than say, a 17-year-old, who presumably has more independence, has a greater likelihood of having engaged in risky and reward-seeking behavior, and has a different appreciation of money (the most commonly used reward in these studies). As such, it is time for the field to set standards on how adolescents are classified; this is particularly crucial now that we have evidence that developmental changes follow a nonlinear pattern in many brain regions that peaks in mid-adolescence (Shaw et al., 2008). At the very least, investigators should make a more concerted effort to report how the age groups were defined. These definitions might include a particular age, puberty, or year in school (e.g., only high school students). While obtaining a broad age range is typically the ideal standard in developmental work to examine developmental change, this approach is only useful if the analyses are conducted in such a way as to appreciate the age and developmental continuum. That is, a broad age range that includes early-, middle- and late-adolescence is only developmentally informative if age is included as a regressor to examine individual variability across development. Instead, all studies described above group the "adolescent" sample and compare it to the comparison group, without taking advantage of the developmental distribution. By the time the study is whittled down to a summary, the generalized message neglects to highlight the significant variability in age.

\section{Comparison groups}

Identifying the appropriate comparison group for adolescents is almost as difficulty as defining adolescence. This identification is challenging because the boundaries between child and adolescent and adolescent and adult are often murky. While some investigators would classify a 12-year-old as a child (van Leijenhorst et al., 2009), others would include that same child in the adolescent group (Bjork et al., 2004; May et al., 2004; Ernst et al., 2005). Similarly, most neuroimaging studies, including developmental and adult studies, include 18- and 19-year-olds as the adult group. This practice has likely arisen for two primary reasons: (1) in the United States, 18 -year-olds are defined by law as adults and (2) college students are an easy subject pool for recruitment purposes. This inclusion persists despite the fact that numerous studies have documented the protracted development of the brain through the mid- to latetwenties (Giedd, 2004) and the questionably mature disposition of individuals in this late adolescent age range. As such, it is quite possible that individuals who are only a few months apart in age (e.g., a 17-year-old and an 18-year-old) are classified as an adolescent 
and adult, respectively (Geier et al., 2009) which begs the question of whether the adult comparison group is truly an accurate comparison group.

\section{Task design}

Despite asking basically the same question (what is the developmental trajectory of dopamine-rich striatal circuitry in response to reward?), no two experimental paradigms described here are alike. While some focused on reward magnitude (Bjork et al., 2004; Galván et al., 2006), others manipulated reward probability (May et al., 2004; van Leijenhorst et al., 2009) or both (Ernst et al., 2005; Eshel et al., 2007). Further, in all but one study (van Leijenhorst et al., 2009), rewards were dependent on participants' behavioral response including reaction time (e.g., Bjork et al., 2004) and response accuracy (Ernst et al., 2005; Galván et al., 2006; Eshel et al., 2007). Given known developmental differences in reaction time speed and accuracy ability, the difficulty of the task could have had large influence on neural activation patterns.

Another obvious difference between the studies listed in Table 1 is the wide range of tasks used and the degree to which they were developmentally appropriate. Task choice is not a trivial issue, as differences in task engagement and comprehension can have significant effects on neural activation. While some studies designed the tasks to maximize the probability that developmental populations would find them engaging (Galván et al., 2006; van Leijenhorst et al., 2009), such as through the use of cartoon-like stimuli and by describing the task as a video game (e.g., "your goal is to help the pirate in this video game earn as much money as possible"), others simply implemented tasks that were designed for adults (e.g., Bjork et al., 2004; May et al., 2004). This latter approach is problematic for several reasons. First, the use of fMRI tasks designed for adults is done under the assumption that youth will find the adult-appropriate tasks as engaging as adults do. Second, this also assumes that children and adolescents will comprehend the tasks as well as adults. Third, this approach may be an unfortunate illustration of a broader negligence of making special considerations when studying children and adolescents. For instance, if the investigators are comfortable using tasks that will likely be uninteresting to children and adolescents, one might wonder if the investigators similarly neglected to implement special child-friendly scanning practices (e.g., ensuring the child is comfortable and that the experience is as anxiety-reducing as possible). To ensure making the tasks as youth-friendly as possible, some suggestions include using cartoon or otherwise animated stimuli, ensuring proper response time for children (as a plethora of studies have shown that children have longer reaction times than adults), and making the task as simple as possible without multiple conditions and rules that the child needs to hold online. For example, while seven predictive cues might be reasonable for an adult to keep in mind in the MID task (Knutson et al., 2001), adolescents may find this task demand more difficult (Bjork et al., 2004) and subsequently become less engaged in the task. This could eventually lead to less neural activation, as compared to the relatively more engaged adults.

\section{Task analyses}

An additional consideration that almost certainly contributed to differences in results is the stage of reward processing that was analyzed. All of these fMRI tasks included three basic stages: cue presentation, anticipation of reward following behavioral response, and feedback. Of the studies reviewed here, three studies examined anticipation of reward (Bjork et al., 2004; Galván et al., 2006; Eshel et al., 2007), three studies analyzed responses to feedback (Bjork et al., 2004; Ernst et al., 2005; van Leijenhorst et al., 2009) and one study did not distinguish between stages and instead analyzed the entire trial (May et al., 2004). The difficulty in analyzing these different stages of reward processing is that temporally proximal events (e.g., the cue and anticipation phase) are difficult to parse out in fMRI analyses. In practice, this means that while only one phase was of interest, MR signal from the other stages may have bled into activation. In other words, while researchers may have intended to examine one aspect of the task, they may have been measuring (and reporting) another aspect of the task. Without the raw data, it is impossible to glean from the papers if this was the case. This possibility may explain the different results reported even when the focus of analysis was the same. For instance, while Bjork et al. (2004) and Galván et al. (2006) both examined the anticipation phase, their data are completely opposite. Also, while Ernst et al. (2005) and van Leijenhorst et al. (2009) report greater ventral striatal activation in adolescents compared to adults during feedback, Bjork et al. (2004) failed to detect any activation differences between groups in any of the feedback contrasts.

A recent study by Geier et al. (2009) illustrates how adolescents may have distinct activation profiles during different stages of the task. These authors cleverly designed the task precisely to be able to deconvolve the distinct stages of the task. During the cue component, adolescents showed an attenuated response in the ventral striatum compared to adults. However, during reward anticipation, the same adolescents showed heightened activity in the same region, as compared to adults. Collectively, these data suggest that temporally distinct aspects of reward tasks may yield significantly different results and should be carefully considered when making sweeping generalizations about the adolescent striatum and reward sensitivity.

\section{Baseline issues}

The interpretation of functional imaging studies of development is dependent on the sensitivity and accuracy of the imaging methods used to detect these changes (Kotsoni et al., 2006). As the blood oxygen level dependent (BOLD) signal is used as a measure of brain activity in most fMRI studies, a variety of variables including heart rate, heart rate variability and respiration can influence the hemodynamic response. For instance, heart rate and respiratory rate in children are nearly twice those in adults (Kotsoni et al., 2006). These physiological differences across development are a significant concern in developmental neuroimaging studies because they can introduce greater noise in echo planar and spiral imaging due to movement of lungs and diaphragm (van de Moortele et al., 2002). As such, these developmental differences should be taken into consideration when identifying an appropriate baseline. Thomason et al. (2005) examined how developmental differences in respiration influenced the fMRI signal while participants breathed normally in the scanner without engaging in a task. They found that in addition to greater noise in the children's data, this noise contributed to increased "baseline" activation in children's relative to adult's percent signal change. As passive rest 
in the scanner (similar to the instructions Thomason's participants received) is commonly used as the baseline condition by which all cognitive task conditions are compared, these differences can have significant and deleterious influence on fMRI results and interpretations. This broader discussion of baseline issues is not new, as Schlaggar et al. (2002) have raised the problem of appropriate comparison tasks previously. Whether children (and adolescents) display increased or decreased resting baseline states will influence the final outcome and interpretations of results when their data are compared to adults' data if the baseline problem is not taken into consideration and controlled for during task design and data analysis.

At least three types of baselines were used in the studies described here. Bjork et al. (2004) defined the baseline as the mean signal value averaged across the entire time series. In the Ernst et al. (2005) paper, 18 (of 129) trials were fixation trials that served as baseline. That is, all contrasts of interest were compared to trials in which the participant was presumed to be doing nothing but staring at a fixation cross (refer to Thomason et al., 2005 above to note how this may be problematic). Similarly, Galván et al. (2006) used the intertrial interval as the relative baseline, during which the participant was presented with a fixation cross. Finally, van Leijenhorst et al. (2009) and Geier et al. (2009) did not define an implicit baseline and instead generated contrast images between different trial types (e.g., certain versus uncertain reward trial types). All authors presumably had good reason to choose the baseline they did and there is no standard baseline in the field but, clearly, small differences in baseline can have dramatic effects on final results. For instance, if adolescents have a higher (or lower) resting baseline than adults, the subtraction method (e.g., comparing image contrasts) used in fMRI analyses may lead to incorrect interpretations.

While agreeing upon a standard baseline is neither feasible nor optimal, as nuances in questions and experimental tasks warrant individual baseline requirements, there are ways to ensure that the chosen baseline in individual studies is comparable across groups. One way to circumvent these inherent developmental differences in resting fMRI signal is to establish separate baselines for each group and then compare task conditions within-group. Several neuroimaging software packages, such as FSL, allow for this type of analysis without compromising statistical group comparisons. A second way is to first confirm that signal activation differences for the baseline condition do not significantly differ between age groups prior to subsequent cognitive task comparisons. Finally, a different approach would be to compare only youth and adults who show similar baseline activation patterns. This approach would be similar to post hoc performance-matching described previously for behavioral data (Schlaggar et al., 2002).

\section{INDIVIDUAL DIFFERENCES IN REWARD SENSITIVITY}

Although the work presented thus far suggests that adolescence is a heightened period of reward sensitivity, not all adolescents are reward-seekers. The importance of examining individual differences in behavior and neural activity has been appreciated in adult samples (e.g., Tom et al., 2007) but less work has been conducted in developmental populations. Reward-seeking and risk-taking behaviors (e.g., gambling and illicit drug use) are more frequent in individuals with a particular behavioral trait, such as elevated novelty and sensation-seeking (Willis et al., 1994). Relevant to this review is that anticipatory activation of the ventral striatum predicts reward-related risks at an individual differences level (Montague and Berns, 2002; Matthews et al., 2004; Kuhnen and Knutson, 2005). For instance, individuals who show greater activation in the ventral striatum prior to a gambling choice are more likely to make a risky, rather than safe, choice (Kuhnen and Knutson, 2005). More generally, previous studies have documented striking individual differences in the efficiency of cognitive control (Fan et al., 2002), which is necessary for self-regulation in rewarding situations. In fact, the ability to direct attention away from rewarding stimuli during a delay of gratification task in toddlers predicts cognitive control later in life (Eigsti et al., 2006). Together, these studies underscore the importance of taking into consideration individual differences in experience, behavior and neural activation when examining complex brain-behavior operations such as reward processing in developmental populations. In a recent study (Galván et al., 2007), we examined individual differences to help disentangle the complexities that underlie increased vulnerability in some individuals to reward-driven behaviors and negative outcomes, such as addiction. Our approach was to examine the association between activity in reward-related neural circuitry in anticipation of a large monetary reward with personality trait measures of risk-taking and impulsivity in adolescence. fMRI scans and anonymous self-report rating scales of risky behavior, risk perception and impulsivity were acquired in individuals between the ages of 7 and 29 years. The main finding was that there was a positive association between NAcc activity and the likelihood of engaging in risky behavior across development; that is, individuals more likely to report higher frequency of risky behavior in "real-life" recruited the ventral striatum the most in the lab. These findings suggest that during adolescence, some individuals may be more prone to engage in risky behaviors due to developmental changes dopamine-rich regions in concert with variability in a given individual's predisposition to engage in risky behavior. These studies are a good starting point to investigate the role of individual differences in reward sensitivity. However, future work also needs to examine the neural correlates of reward that incorporates sex, age, pubertal stage and ethnic differences.

\section{WHAT IS REWARDING TO A HUMAN ADOLESCENT?}

The majority of studies reviewed above used money as a reward probe, as it is an easy reward to manipulate, elicits robust recruitment of dopamine-rich circuitry, and has been used extensively in adult models of reward. However, adolescents are motivated by more than simply monetary rewards and studies that take advantage of social, novelty and primary reinforcing rewards that also motivate adolescents may shed new light on the reward system. What is rewarding changes with development, so what adolescents deem uniquely rewarding, relative to children and adults, may inform the field about the underlying dopamine system. For instance, while children are most rewarded by primary reinforcers, such as sugar, adolescents find peer interactions more rewarding than children and adults (Csikszentmihalyi et al., 1977). One study showed increased recruitment of the ventral striatum to passive viewing of images of socially desirable, but not undesirable peers (Guyer 
et al., 2009). Without an appropriate manipulation of the socially desirable peers as rewarding stimuli, it is impossible to know if, indeed, adolescents find socially desirable peers more rewarding than others but this study does implicate dopamine-rich circuitry in adolescent sensitivity to social interactions. As such, what is rewarding and the context in which the rewards are presented are important factors to consider when comparing motivation, behavior and underlying reward circuitry in adolescents relative to other groups. This is particularly relevant to the well-characterized risk-taking behavior in adolescents (Steinberg, 2004). Relative to adults or children, adolescents are more likely to categorize risk-taking as "fun" or rewarding (Maggs et al., 1995); this suggests that in response to a risky opportunity, adolescents may be more likely to engage the dopamine system than other age groups, which may contribute to their increased risk-taking tendencies. This phenomenon has been reviewed extensively elsewhere (e.g., Steinberg, 2004; Ernst and Mueller, 2008; Somerville et al., 2009).

\section{FUTURE AREAS OF INQUIRY}

This review did not include the extensive literature on hormonal development as they relate to behavioral changes during adolescence as it has been reviewed numerous times elsewhere (Spear, 2000). However, complex interactions between the dopamine system and changes in hormones during adolescence likely contribute to the expressed reward-related behaviors. In future work, designing experiments that can assess how the function of dopamine-rich circuitry is mediated by changes in hormones may provide useful insights into this complex association.

Also, further examination of how changes in sleep patterns influence neural function during adolescence will be a useful area of inquiry. Mounting evidence suggests that sleep is critical for brain function and development (Benca, 2004; Hagenauer et al., 2009). Recent examination of this critical question provides invaluable insight into how normally occurring changes in sleep patterns might exacerbate detrimental adolescent-typical behaviors (Dahl and Lewin, 2002; Holm et al., 2009). Holm et al. (2009) show that poor sleep quality and fewer minutes of sleep were associated with blunted striatal activity during reward anticipation and outcome (Holm et al., 2009). These data highlight the importance of considering contextual effects on reward-related neural sensitivity across development.

Various reports have noted sexual dimorphism in dopamine system development in animal models (Andersen et al., 1997) and structural MRI work (Giedd et al., 2004). However, this area of research has been relatively under-studied in functional MRI studies, probably because of practical constraints imposed by relatively limited sample sizes in these studies. This effect is a critical

\section{REFERENCES}

Andersen, S. L., Dumont, N. L., and Teicher, M.H. (1997). Developmental differences in dopamine synthesis inhibition by 7-OH-DPAT. Naunyn Schmiedebergs Arch. Pharmacol. 356, 173-181.

Andersen, S. L., and Gazzara, R. A. (1993). The ontogeny of apomorphine-induced alterations of neos-

area of study as there are prominent sex differences in the onset and maintenance of several mental health disorders that may be related to aberrant dopamine functioning (Paus et al., 2008).

\section{CONCLUSIONS}

This review began with the following question: is the dopamine system hypo- or hyper-responsive to rewards during adolescence? The investigations described in this review provide unequivocal evidence that the reward system undergoes massive changes during adolescence. Further, they show strong support for the hypothesis that the dopamine system is hyper-responsive, or over-engaged, in response to rewards during adolescence. While initial neuroimaging work (Bjork et al., 2004) seemed to provide support for hyporesponsive reward system hypothesis, numerous studies since have instead yielded data that provide support for an overactive reward system during adolescence. As such, the field seems to be converging on this latter conclusion (Casey et al., 2008; Steinberg, 2008; Ernst et al., 2009; Somerville et al., 2009). However, subtle nuances in experimental manipulation, interpretation and environmental context have significant effects on this generalization. As best illustrated in recent work by Geier et al. (2009), different aspects of reward are paralleled by distinct neural sensitivity in adolescence, such that initial presentation of a reward-predicting cue does not lead to similar hyperactivity as the anticipation of upcoming reward. In our own work, human adolescents showed increased activation, relative to children and adults, in the dopamine-rich NAcc in response to high reward but showed diminished activation in this same region in response to low reward (Galván et al., 2006). Thus, what is rewarding to an adolescent will influence circuitry implicated in reward and risk-taking and, presumably, subsequent behavior. Reward value is not absolute and rewards are instead appreciated in the context of other available rewards. Adolescents may be particularly sensitive to these changing contexts.

In sum, while there is no doubt that the reward system undergoes dramatic developmental changes during adolescence, the precise features of these maturational events cannot easily be determined and will require further exploration, in both the animal and human literatures. By rooting research on the dopamine system in animal findings, we can begin to constrain interpretations of data from the human work, to better understand what precisely is changing in the striatal dopamine system that predisposes adolescents to engage in high reward-seeking behaviors.

\section{ACKNOWLEDGMENTS}

The author acknowledges the helpful comments by members of the Galván Lab, two anonymous reviewers and previous discussions with Brad Schlaggar regarding baseline issues.

Andersen S. L., and Teicher, M. H. (2000). Dopamine receptor pruning in prefrontal cortex during the periadolescent period in rats. Synapse 37 167-169.

Andersen, S. L., Thompson, A. P., Krenzel, E., and Teicher, M. H. (2002). Pubertal changes in gonadal hormones do not underlie adolescent dopamine receptor overproduc- tion. Psychoneuroendocrinology 27, 683-691.

Bandettini, P. A., and Ungerleider, L. G. (2001). From neuron to BOLD: new connections. Nat. Neurosci. 412 864-866.

Benca, R. M. (2004). Regulation of sleep and arousal: Introduction to part VII. Ann. N. Y. Acad. Sci. 1021, 260-261. 
Berridge, K. C., and Robinson, T. E. (1998). What is the role of dopamine in reward: hedonic impact, reward learning, or incentive salience? Brain Res. Brain Res. Rev. 28, 309-369.

Bjork, J. M., Knutson, B., Fong, G. W., Caggiano, D. M., Bennett, S. M., and Hommer, D. W. (2004). Incentiveelicited brain activation in adolescents: similarities and differences from young adults. J. Neursoci. 24, 1793-1802.

Blum, K., Braverman, E., Holder, J., Lubar, J., Monastra, V., Miller, D., Lubar, J., Chen, T., and Comings, D. (2000). Reward deficiency syndrome: a biogenetic model for the diagnosis and treatment of impulsive, addictive and compulsive behaviors. J. Psychoactive Drugs 2, 1-112

Blum, K., Cull, J. G., Braverman, E. R., and Comings, D. E. (1996). Reward deficiency syndrome. Am. Sci. 84, 132-145.

Bolanos, C. A., Glatt, S. J., and Jackson, D. (1998). Subsensitivity to dopaminergic drugs in periadolescent rats: a behavioral and neurochemical analysis. Dev. Brain Res. 111, 25-33.

Brenhouse, H. C., Sonntag, K. C., and Andersen, S. L. (2008). Transient D1 dopamine receptor expression on prefrontal cortex projection neurons: relationship to enhanced motivational salience of drug cues in adolescence. $J$. Neurosci. 28, 2375-2382.

Casey, B. J., Galván, A., and Hare, T. A. (2005). Changes in cerebral functional organization during cognitive development. Curr. Opin. Neurobiol. 15, 239-244.

Casey, B. J., Getz, S., and Galván, A. (2008). The adolescent brain. Dev. Rev. 28, 62-77.

Caviness, V., Kennedy, D., Richelme, C., Rademacher, J., and Filipek, P. (1996). The human brain age 7-11 years: a volumetric analysis based on magnetic resonance images. Cereb. Cortex 6, 726-736.

Chambers, R. A., Taylor, J. R., and Potenza, M.N.(2003).Developmental neurocircuitry of motivation in adolescence: a critical period of addiction vulnerability. Am. J. Psychiatry 160, 1041-1052.

Csikszentmihalyi, M., Larson, R., and Prescott, S. (1977). The ecology of adolescent activity and experience. $J$. Youth Adolesc. 6, 281-294.

Dahl, R.E. (2004). Adolescent brain development: a period of vulnerabilities and opportunities. Ann. N. Y. Acad. Sci. 1021, 1-22.

Dahl, R. E., and Lewin, D. S. (2002). Pathways to adolescent health sleep regulation and behavior. J. Adolesc. Health 31, 175-184.

DeGraff, C., and Zandstra, E. (1999). Sweetness intensity and pleasantness in children, adolescents and adults. Physiol. Behav. 67, 513-520.

Eigsti, I. M., Zayas, V., Mischel, W., Shoda, Y.,Ayduk,O., Dadlani, M. B.,Davidson, M. C., Lawrence Aber, J., and Casey, B. J. (2006). Predicting cognitive control from preschool to late adolescence and young adulthood. Psychol. Sci. $17,478-484$.

Ernst, M., and Mueller, S. C. (2008). The adolescent brain: insights from functional neuroimaging research. Dev Neurobiol 68, 729-743.

Ernst, M., Nelson, E. E., Jazbec, S. P., McClure, E. B., Monk, C. S., Leibenluft, E., Blair, J., and Pine, D. S. (2005). Amygdala and nucleus accumbens in responses to receipt and omission of gains in adults and adolescents. Neuroimage 25, 1279-1291.

Ernst, M., Romeo, R. D., and Andersen, S. L. (2009). Neurobiology of the development of motivated behaviors in adolescence: a window into a neural systems model. Pharmacol. Biochem. Behav. 93, 199-211.

Eshel, N., Nelson, E. E., Blair, R. J., Pine, D. S., and Ernst, M. (2007). Neural substrates of choice selection in adults and adolescents: development of the ventrolateral prefrontal and anterior cingulate cortices. Neuropsychologia $45,1270-1279$.

Fan, J., McCandliss B. D., Sommer, T., Raz, A., and Posner, M. I. (2002). Testing the efficiency and independence of attentional networks. J. Cogn. Neurosci. 14 340-347.

Galván, A., Hare, T. A., Parra, C. E., Penn, J., Voss, H., Glover, G., and Casey, B. J. (2006). Earlier development of the accumbens relative to orbitofrontal cortex might underlie risk-taking behavior in adolescents. J. Neurosci. 26, 6885-6892

Galván, A., Hare, T. A., Voss, H., Glover, G. and Casey, B. J. (2007). Risk-taking and the adolescent brain: who is at risk? Dev. Sci. 10, 1-7.

Geier, C. F., Terwilliger, R., Teslovich, T., Velanova, K., and Luna, B. (2009). Immaturities in reward processing and its influence on inhibitory control in adolescence. Cereb. Cortex [Epub ahead of print].

Giedd, J.N. (2004). Structural MRI of the Adolescent Brain. Ann. N. Y. Acad. Sci. 1021:77.

Giedd, J. N., Blumenthal, J., Jeffries, N. O., Castellanos, F.X,. Liu, H., Zijdenbos, A., Paus, T., Evans, A. C., and Rapoport, J. L. (1999). Brain development during childhood and adolescence: a longitudinal MRI study. Nat. Neurosci. 2, 861-863.

Giedd, J. N., Snell, J., Lange, N., Rajapakse, J., Casey, B., Kozuch, P., Vaituzis, A.,
Vauss, Y., Hamburger, S., Kaysen, D., and Rapoport, J. L. (1996). Quantitative magnetic resonance imaging of human brain development: ages 4-18. Cereb. Cortex 6. 551-560.

Gogtay, N., Giedd, J. N., Lusk, L., Hayashi, K. M., Greenstein, D., Vaituzis, A. C. Nugent, T. F. III, Herman, D. H., Clasen, L. S., Toga, A. W., Rapoport, J. L., and Thompson, P. M. (2004) Dynamic mapping of human cortical development during childhood through early adulthood. Proc. Natl. Acad. Sci. U.S.A. 101, 8174-8179.

Guyer, A. E., McClure-Tone, E. B., Shiffrin, N. D., Pine, D. S., and Nelson, E. E. (2009). Probing the neural correlates of anticipated peer evaluation in adolescence. Child Dev. 80, 1000-1015.

Hagenauer M. H., Perryman, J. I., Lee. T.M., and Carskadon, M. A. (2009) Adolescent changes in the homeostatic and circadian regulation of sleep. Dev Neurosci. 31, 276-284.

Holm, S. M., Forbes, E. E., Ryan, N. D., Phillips, M. L., Tarr, J. A., and Rahl, R. E. (2009). Reward-related brain function and sleep in pre/early pubertal and mid/ate pubertal adolescents. $J$. Adolesc. Health 45, 319-320.

Kennedy, D. N., Haselgrove, C., and McInerney, S. (2003). MRI-based morphometric of typical and atypical brain development. Ment. Retard Dev Disabil. Res. Rev. 9, 155-160.

Knutson, B., Fong, G. W., Adams, C. M., Varner, J. L., and Hommer, D. (2001). Dissociation of reward anticipation and outcome with event-related fMRI Neuroreport 12, 3683-3687.

Koob, G. F., and Swerdlow, N. R. (1988). The functional output of the mesolimbic dopamine system. Ann. N. Y. Acad Sci. 537, 216-227.

Kotsoni, E., Byrd, D., and Casey, B. J. (2006). Special considerations for functional magnetic resonance imaging of pediatric populations. J. Magn. Reson. Imaging 23,877-886.

Kuhnen, C. M., and Knutson, B. (2005) The neural basis of financial risk taking. Neuron 47, 763-770.

Larson, R., and Asmussen, L. (1991). Anger, Worry, and Hurt in Early Adolescence: An Enlarging World of Negative Emotions. New York, NY: Aldine de Gruyter.

Laviola, G., Macri, S., Morley-Fletcher, S., and Adriani, W. (2003). Risk-taking behavior in adolescent mice: psychobiological determinants and early epigenetic influence. Neurosci. Biobehav. Rev. 27, 19-31.

Laviola, G., Pascucci, T., and Pieretti, S. (2001). Striatal dopamine sensitization to $\mathrm{D}$-amphetamine in periadolescent but not in adult rats. Pharmacol Biochem. Behav. 68, 115-124.
Logothetis, N., Pauls, J., Augath, M. Trinath, T., and Oeltermann, A. (2001). Neurophysiological investigation of the basis of the fMRI signal. Nature 412,150-157.

Maggs, J.L,Almeida, D. M., and Galambos, N. L. (1995). Risky business: the paradoxical meaning of problem behavior for young adolescents. J. Early Adolesc. $15,344-362$.

Matthews, S. C., Simmons, A. N., Lane, S. D., and Paulus, M. P. (2004). Selective activation of the nucleus accumbens during risk-taking decision making. Neuroreport 15, 2123-2127.

May, J. C., Delgado, M. R., Dahl, R. E., Stenger, V. A., Ryan, N. D., Fiez, J. A., and Carter, C. S. (2004). Event-related functional magnetic resonance imaging of reward-related brain circuitry in children and adolescents. Biol. Psychiatry 55, 359-366.

Montague, D. M., Lawler, C. P., Mailman, R. B., and Gilmore, J. H. (1999). Developmental regulation of the dopamine D1 receptor in human caudate and putamen. Neuropsychopharmacology 21, 641-649.

Montague, P. R., and Berns, G. S. (2002). Neural economics and the biological substrates of valuation. Neuron 36 , 265-284.

Montague, P. R., Hyman, S. E., and Cohen, J. D. (2004). Computational roles for dopamine in behavioral control. Nature 431,379-387.

Palacios, J. M., Camps, M., Corte, R., and Probst, A. (1988). Mapping dopamine receptors in the human brain.J. Neural. Transm. Suppl. 27, 227-235.

Panksepp,J.(1998).AffectiveNeuroscience. New York, Oxford University Press.

Paus, T., and Keshavan, M, Giedd, J. N. (2008). Why do so many psychiatric disorders emerge during adolescence? Nat. Rev. Neurosci. 9, 947-957.

Rutter, M., Graham, P., Chadwick, O., and Yule, W. (1976). Adolescent turmoil: fact or fiction? J. Child Psychol. Psychiatry 17, 35-56.

Schlaggar, B. L., Brown, T. T., Lugar, H. M., Visscher, K. M., Miezin, F. M., and Petersen, S. E. (2002). Functional neuroanatomical differences between adults and school-age children in the processing of single words. Science 296 , 1476-1479.

Schultz, W. (1998). Predictive reward signal of dopamine neurons. $J$. Neurophysiol. 80, 1-27.

Seeman, P., Bzowej, N. H., Guan, H.-C., Bergeron, C., Becker, L. E., Reynolds, G. P., Bird, E. D., Riederer, P., Jellinger, K., Watanabe, S., and Tourtellotte. W. W. (1987). Human brain dopamine receptors in children and aging adults. Synapse 1, 399-404. 
Shaw, P., Kabani, N. J., Lerch, J. P., Eckstrand, K., Lenroot, R., Gogtay, N., Greenstein, D., Clasen, L., Evans, A., Rapoport, J. L., Giedd, J. N., and Wise, S. P. (2008). Neurodevelopmental trajectories of the human cerebral cortex. $J$. Neurosci. 28, 3586-3594.

Somerville, L. H., Jones, R. M., and Casey, B. J. (2009). A time of change: Behavioral and neural correlates of adolescent sensitivity to appetitive and aversive environmental cues. Brain Cogn. [Epub ahead of print].

Sowell, E. R., Peterson, B. S., Thompson, P. M., Welcome, S. E., Henkenius, A. L., and Toga, A. W. (2003). Mapping cortical change across the human life span. Nat. Neurosci. 6, 309-315.

Sowell, E. R., Thompson, P.M., Holmes, C. J., Jernigan, T.L., and Toga, A. W. (1999). In vivo evidence for post-adolescent brain maturation in frontal and striatal regions. Nat. Neurosci. 2, 859-861.

Spear, L. P. (2000). The adolescent brain and age-related behavioral manifestations. Neurosci. Biobehav. Rev. 24, 417-463.

Stamford, J. A. (1989). Development and ageing of the rat nigrostriatal dopamine system studied with fast cyclic voltammetry. J. Neurochem. 52, 1582-1589.

Steinberg, L. (2004). Risk taking in adolescence: what changes, and why? Ann. N. Y. Acad. Sci. 1021, 51-58.

Steinberg,L. (2005). A social neuroscience perspective on adolescent risk-taking. Dev. Rev. 28, 78-106.

Steinberg, L. (2008). A social neuroscience perspective on adolescent risk- taking. Dev. Rev. 28, 78-106.

Tarazi, F. I., Tomasini, E. C., and Baldessarini, R. J. (1998). Postnatal development of dopamine D4-like receptors in rat forebrain regions: comparison with D2-like receptors. Dev. Brain Res. 110, 227-233.

Tarazi, F. I., Tomasini, E. C., and Baldessarini, R. J. (1999). Postnatal development of dopamine D1-like receptors in rat cortical and striatolimbic brain regions: an autoradiographic study. Dev. Neurosci. 21, 43-49.

Teicher, M. H., Andersen, S. L., and Hostetter, J. C. Jr. (1995). Evidence for dopamine receptor pruning between adolescence and adulthood in striatum but not nucleus accumbens. Dev. Brain Res. 89, 167-172.

Teicher, M. H., Barber, N. I., Gelbard, H. A., Gallitano, A. L., Campbell,
A, Marsh, E., and Baldessarini, R. J. (1993). Developmental differences in acute nigrostriatal and mesocorticolimbic system response to haloperidol. Neuropsychopharmacology 9 , 147-156.

Thomason, M.E., Burrows, B. E., Gabrieli, J. D. E., and Glover, G. H. (2005). Breath holding reveals differences in fMRI BOLD signal in children, and adults. Neuroimage 25, 824-837.

Tom, S. M., Fox, C. R., Trepel, C., and Poldrack, R. A. (2007). The neural basis of loss aversion in decisionmaking under risk. Science 315, 515-518.

van de Moortele, P. F., Pfeuffer, J., Glover, G. H., Ugurbil, K., and Hu, X. (2002). Respiration-induced B0 fluctuations and their spatial distribution in the human brain at 7 Tesla. Magn. Reson. Med. 47, 888-895.

van Leijenhorst, L., Zanolie, K., van Meel, C. S., Westenberg, P. M, Rombouts, S A., and Crone, E. A. (2009). What motivates the adolescent? Brain regions mediating reward sensitivity across adolescence. Cereb. Cortex. [Epub ahead of print].

Watson, D., and Clark, L. (1984). Negative affectivity: the disposition to experi- ence aversive emotional states. Psychol. Bull. 96, 465-490.

Willis, T. A., Vacarro, D., and McNamara, G. (1994). Novelty seeking, risk taking, and related constructs as predictors of adolescence substance abuse: an application of Cloniger's theory. J. Subst. Abuse 6, 1-20.

Conflict of Interest Statement: The author declares that the research was conducted in the absence of any commercial or financial relationships that could be construed as a potential conflict of interest.

Received: 01 September 2009; paper pending published: 03 September 2009; accepted: 20 January 2010; published online: 12 February 2010.

Citation: Galvan A (2010) Adolescent development of the reward system. Front. Hum. Neurosci. 4:6. doi: 10.3389/neuro.09.006.2010

Copyright (c) 2010 Galvan. This is an open-access article subject to an exclusive license agreement between the authors and the Frontiers Research Foundation, which permits unrestricted use, distribution, and reproduction in any medium, provided the original authors and source are credited. 